\title{
In vitro analysis of microRNA-26a in chronic lymphocytic leukemia cells
}

\author{
JING LI and CHANG-KUI SUN \\ Blood Group Reference Laboratory, Shandong Blood Center, Jinan, Shandong 250014, P.R. China
}

Received March 15, 2018; Accepted September 18, 2018

DOI: $10.3892 / \mathrm{ijmm} .2018 .3925$

\begin{abstract}
RNA (miRNA)-26a-loaded liposomes were prepared in the present study for effective treatment of leukemia. The results demonstrated that miRNA-26a reduced the viability of chronic lymphocytic leukemia (CLL) cells in a concentration-dependent manner. Cells treated with miRNA-26a-loaded liposomes exhibited increased rates of apoptosis, as determined by flow cytometry and Hoechst 33342 staining. Western blot analysis revealed an increased apoptotic effect of miRNA-26a-loaded liposomes compared with control. Treatment with these liposomes resulted in significant downregulation of the expression of the miRNA-26a target genes, myeloid cell leukemia 1 and cyclin-dependent kinase 6 . Taken together, the results of the present study indicate that miRNA-26a exerts apoptosis-inducing and anticancer effects on leukemia cells, suggesting therapeutic potential. This approach may be possible to extrapolate to other neoplasms, including lymphomas and acute myeloid leukemia.
\end{abstract}

\section{Introduction}

Chronic lymphocytic leukemia (CLL) is a type of blood cancer that is heterogeneous at the clinical and cellular levels $(1,2)$, and which arises due to uncontrolled proliferation of lymphocytes that accumulate in the blood and bone marrow. These immature cells can permeate other organs, including the liver, kidney and central nervous system, which can ultimately result in fatality $(2,3)$. Patients with acute myeloid leukemia (AML) often exhibit characteristic mutations and dysregulated gene expression, both of which contribute to the generally poor prognosis of the disease (4). Despite significant advances in our understanding of the biology of leukemia, an optimal treatment regime for CLL is lacking (5-7). Current treatment

Correspondence to: Dr Jing Li, Blood Group Reference Laboratory, Shandong Blood Center, 22 Shanshi East Road, Jinan, Shandong 250014, P.R. China

E-mail: leeannapsho@yahoo.com

Key words: leukemia, apoptosis, miRNA-26a, anticancer effect, liposome regimens rely on chemotherapy, which involves systemic drug administration. However, the efficacy of chemotherapy is limited due to immediate clearance of the drugs from blood circulation. In addition, the development of resistance to chemotherapy drugs is a major reason for the poor prognosis of leukemia (8). The development of resistance is attributed to the mechanism of action of chemotherapeutic drugs, which activate intrinsic apoptosis pathways (9). In the case of leukemia, however, apoptosis pathways are inhibited by Abl expression and a lack of FAS receptors. Generally, these can be reversed by administration of high doses of anticancer drugs, but this is accompanied by marked systemic toxic effects in healthy tissues (10). Therefore, there is a requirement to identify non-chemotherapeutic treatments for leukemia with improved efficacy and reduced side effects.

MicroRNAs (miRNAs) are short noncoding RNAs that are involved in regulating the expression of their target genes (11). Certain miRNAs have been reported to be directly responsible for leukemogenesis and are involved in the prognosis of cancer. miRNAs regulate the expression of genes at the posttranscriptional level by altering messenger RNA (mRNA), thereby modifying associated biological processes or pathways $(12,13)$. Thus, miRNAs can act as oncogenes or tumor inhibitors. For example, silencing of miR-15a/16-1 in an animal model was reported to result in the development of an indolent form of leukemia (14). Bcl-2 is an miRNA target, and its interaction with miRNA eliminates the expression of Bcl-2, resulting in cell death. The anticancer drug, venetoclax, which inhibits Bcl-2, was recently approved for use in CLL (15). Other miRNAs have also been demonstrated to be useful in the regulation of leukemia, with miRNA-34a reported to downregulate $17 \mathrm{p}$-CLL and halt disease progression $(16,17)$. These studies lay the groundwork for the development of miRNA-based therapies. The present study was performed to examine the effects of miRNA-26a on leukemia cells.

One of the most important concerns in miRNA-based therapy is the delivery strategy. Due to their very low stability in the body, miRNAs require a carrier to elicit their pharmacological therapeutic effects. The development of nanoscale biomaterials is a popular topic of interest for targeted treatment of cancer (18). An ideal delivery system would deliver the maximum amount of drug to the target site without being toxic itself (19). Liposomes are ideal carriers for systemic applications and have been studied in detail in clinical trials (20). Liposomes are biocompatible and of an appropriate size for 
accumulation in tumor tissue. The long half-life of liposomes in the circulation allows for accumulation of the carrier in leukemia cells (21).

The aim of the present study was to design an miRNA-loaded delivery system for the effective treatment of leukemia. miRNA-26a was physically loaded into liposomes and the various biological properties, including cell viability, apoptosis and morphological changes, were studied in vitro.

\section{Materials and methods}

Materials. Cholesterol, 1,2-dioleyl-3-trimethylammoniumpropane(DODAP), 1,2-distearoyl-sn-glycero-3-phosphocholine (DSPC), and N-palmitoyl-sphingosine-1-[succinyl(polyethylene glycol)]2000 (DSPE-PEG) were purchased from Avanti Polar Lipids (Alabaster, AL, USA). All other chemicals were of reagent grade and were used without further purification.

Preparation of miRNA-loaded liposomes. Liposomes were prepared using the thin-film hydration method. In brief, DODAP:CHOL:DSPC:DSPE-PEG were dissolved at a molar ratio of 25:50:23:2 in a mixture of $1 \mathrm{ml}$ of chloroform $(100 \%)$ and methanol (100\%) (4:1). The organic solvent was agitated such that all lipids were dissolved, and removed from the rotary evaporator at $60^{\circ} \mathrm{C}$. Thereafter, the lipid film was hydrated using distilled water at $60^{\circ} \mathrm{C}$ for $15 \mathrm{~min}$ and extruded using a mini-extruder for 21 cycles through a polycarbonate membrane with a pore size of $100 \mathrm{~nm}$. The liposomes thus formed were purified by dialysis for $24 \mathrm{~h}$. Liposomes were stored in glass vials, and $10 \mu \mathrm{g}$ miRNA-26a (3-UCGGAUAGG ACCUAAUGAACUU-5) was added and incubated for $12 \mathrm{~h}$ under constant agitation. The miRNA-loaded liposomes were stored at $4^{\circ} \mathrm{C}$ until further use. The miRNA was complexed with Lipofectamine 2000 (Thermo Fisher Scientific, Inc., Waltham, MA, USA) as a transfection agent and incubated with the cancer cells.

Characterization of liposomes. The miRNA-loaded liposomes were evaluated in terms of particle size and particle-size distribution using a Zetasizer Nano ZS (Malvern Instruments, Worcestershire, UK). The liposomes (dispersed in 0.1X PBS, density, $1 \mathrm{~kg} / \mathrm{m}^{3}$ ) were diluted appropriately in ultra-pure water (density, $997 \mathrm{~kg} / \mathrm{m}^{3}$ ) and experiments were performed in triplicate at room temperature. The morphology of the liposomes was examined by transmission electron microscopy (TEM; Tecnai G2 12 TWIN TEM; FEI; Thermo Fisher Scientific, Inc.). The samples were mixed with $2 \%$ phosphotungistic acid as a counterstain solution for 4 min and placed in a drop onto a copper grid prior to drying. The samples were then analyzed by TEM (x10,000, magnification).

Gel electrophoresis. Physical entrapment of miRNA in liposomes was evaluated by electrophoresis through $2 \%$ agarose gels in Tris-acetate-ethylenediaminetetraacetic acid (EDTA) buffer containing $0.5 \mu \mathrm{g} / \mathrm{ml}$ of GelRED (Biotium, Inc., Fremont, CA, USA). The free miRNA and miRNA-loaded liposomes were mixed with $10 \%$ glycerin, $1 \%$ bromothymol blue and $2 \%$ SDS, subjected to electrophoresis at $120 \mathrm{~V}$ for $20 \mathrm{~min}$, and then photographed using a gel imaging system (ChemiDocTM; Bio-Rad Laboratories, Inc.).
Cytotoxicity assay. CLL cells (American Type Culture Collection; ATCC; Manassas, VA, USA) were maintained in RPMI medium supplemented with $10 \%$ FBS (Lonza Group, Ltd., Basel, Switzerland) and $1 \%$ penicillin-streptomycin antibiotic mixture in an atmosphere of $65 \%$ humidity with $5 \% \mathrm{CO}_{2}$ and $37^{\circ} \mathrm{C}$. The cells were seeded in 96 -well plates at a density of $1.2 \times 10^{4}$ cells per well and incubated for $24 \mathrm{~h}$. The cells were then treated with miRNA-loaded liposomes or blank liposomes $(0.1,1,10,50$ and $100 \mu \mathrm{M})$ and incubated for a further $24 \mathrm{~h}$. The cells were treated for $24 \mathrm{~h}$ with increasing concentrations of miRNA-26a $(25,50$ and $100 \mu \mathrm{M}$ ) to study concentration-dependent cytotoxicity against leukemia cells. Untreated cells were maintained throughout the study period. The cells were treated with $100 \mu 11.25 \mathrm{mg} / \mathrm{ml}$ MTT solution and incubated for $4 \mathrm{~h}$ at $37^{\circ} \mathrm{C}$, after which the formazan crystals were dissolved in DMSO. The absorbance was determined at $570 \mathrm{~nm}$ using a microplate reader (Infinite M200 reader; Tecan, Männedorf, Switzerland). For comparison, NIH-3T3 cells (ATCC) was purchased and grown in RPMI medium supplemented with $10 \%$ FBS (Lonza Group, Ltd.) and 1\% penicillin-streptomycin antibiotic mixture in a humidified atmosphere $(65 \%)$ with $5 \% \mathrm{CO}_{2}$ and $37^{\circ} \mathrm{C}$. The same protocol was followed for MTT assay of these cells.

Hoechst 33342 assay. The cells were seeded in 6-well plates at a density of $3 \times 10^{5}$ cells per well and incubated for $24 \mathrm{~h}$. The cells were then treated with miRNA-loaded liposomes (MRL) or blank liposomes $(25,50$ and $100 \mu \mathrm{M})$, and incubated for a further $24 \mathrm{~h}$. The cells were treated for $24 \mathrm{~h}$ with increasing concentrations of the miRNA-26a $(25,50$ and $100 \mu \mathrm{M})$ to examine concentration-dependent effects on apoptosis. The following day, the cells were washed carefully with ultrapure water and stained with $10 \mu \mathrm{g} / \mathrm{ml}$ Hoechst 22242 for $15 \mathrm{~min}$ at $37^{\circ} \mathrm{C}$. The cells were then fixed with $4 \%$ paraformaldehyde and washed again with PBS. Apoptosis was qualitatively assessed by fluorescence microscopy.

Apoptosis. The cells were seeded in 12-well plates at a density of $2 \times 10^{5}$ cells per well and incubated for $24 \mathrm{~h}$, then treated with miRNA-loaded liposomes or blank liposomes $(25,50$ and $100 \mu \mathrm{M}$ ), and incubated for a further $24 \mathrm{~h}$. The cells were treated with $200 \mu \mathrm{M}$ MRL and incubated for an additional $24 \mathrm{~h}$. The following day, the cells were washed carefully with PBS and centrifuged at $1,300 \mathrm{x} g$ at $4^{\circ} \mathrm{C}$. The cell pellets were resuspended in binding buffer (BD Biosciences, Franklin Lakes, NJ, USA) and incubated with $2.5 \mu \mathrm{l}$ Annexin $\mathrm{V}$ and $2.5 \mu \mathrm{l}$ propidium iodide (PI) (BD Biosciences) for $15 \mathrm{~min}$, followed by flow cytometric analysis (FACSCalibur; BD Biosciences, Franklin Lakes, NJ, USA).

Western blot analysis. Cells were treated with blank liposome and miR-26a-loaded liposomes (25, 50 and $100 \mu \mathrm{M})$, harvested after $24 \mathrm{~h}$ and lysed using radioimmunoprecipitation assay lysis buffer for $15 \mathrm{~min}$ at $24^{\circ} \mathrm{C}$. The lysed cells were centrifuged at $12,000 \mathrm{x}$ g for $15 \mathrm{~min}$ at $4^{\circ} \mathrm{C}$. The supernatant was collected and the protein concentration was determined using a BCA protein assay kit (Thermo Fischer Scientific, Inc.). A total of $25 \mu \mathrm{g}$ protein per lane was separated by $10 \%$ SDS-PAGE and transferred onto polyvinylidene fluoride 


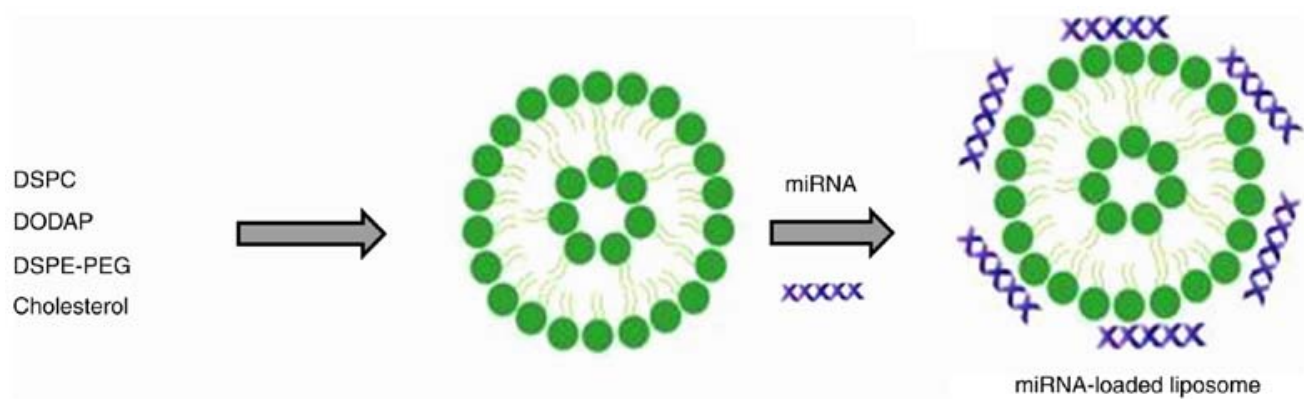

Figure 1. Schematic representation of the preparation of miRNA-26a-loaded liposomes. Cationic liposomes were prepared and electrostatically conjugated with miRNA-26a. miRNA, microRNA.

membranes (Bio-Rad Laboratories, Hercules, CA, USA). The membranes were then blocked with $5 \%$ skimmed milk for $1 \mathrm{~h}$, followed by incubation with the following primary antibodies at $4^{\circ} \mathrm{C}$ overnight: Anti-cyclin-dependent kinase 6 (CDK6; cat. no. 3136; 1:1,000), anti-MCL1 (cat. no. 4572; 1:1,000), BCL2 family apoptosis regulator (BCL2 cat. no. 2870; 1:1,000), anti-poly (ADP-Ribose) polymerase (PARP; cat. no. 9542; 1:1,000) and anti-GAPDH (dilution, 1:1,000; cat. no. 2118; all from Cell Signaling Technology, Inc., Danvers, MA, USA). The following day, the membranes were incubated with horseradish peroxidase-conjugated anti-mouse IgG secondary antibodies (cat. no. 7076; 1:3,000). Images of the blots were obtained using an Odyssey infrared imaging system (LI-COR Biosciences, Lincoln, NE, USA) and quantified using ImageJ software (version 7.0; National Institutes of Health, Bethesda, MD, USA).

Statistical analysis. The data are presented as the mean \pm standard deviation. All analyses were performed with SPSS software (version 17; SPSS, Inc., Chicago, IL, USA). Comparisons between groups were assessed by one-way analysis of variance. In instances of multiple comparisons, analysis of variance was performed, followed by the Scheffé post hoc test. $\mathrm{P}<0.05$ was considered to indicate a statistically significant difference.

\section{Results and Discussion}

Preparation and characterization of miRNA-loaded liposomes. Despite significant advances in our understanding of the biology of leukemia, there remains no optimal treatment for CLL. Current treatment options involve chemotherapy, however, they have poor efficacy due to the immediate clearance of drugs from the circulation and the development of drug resistance. Although miRNAs serve important roles in the pathogenesis of cancer, they can also function as tumor suppressors (22). The more established small interfering RNAs (siRNAs) silence the expression of a single gene, while miRNAs can silence multiple genes simultaneously (23). Therefore, miRNA-based therapy has potential in the treatment of various types of cancer. In the present study, miRNA-26a was selected for the treatment of leukemia cells. Delivery strategy remains an important concern in miRNA-based therapy, as the stability of miRNA in vivo is low. Liposomes are among the most well-studied carrier systems in clinical trials, are highly biocompatible and of

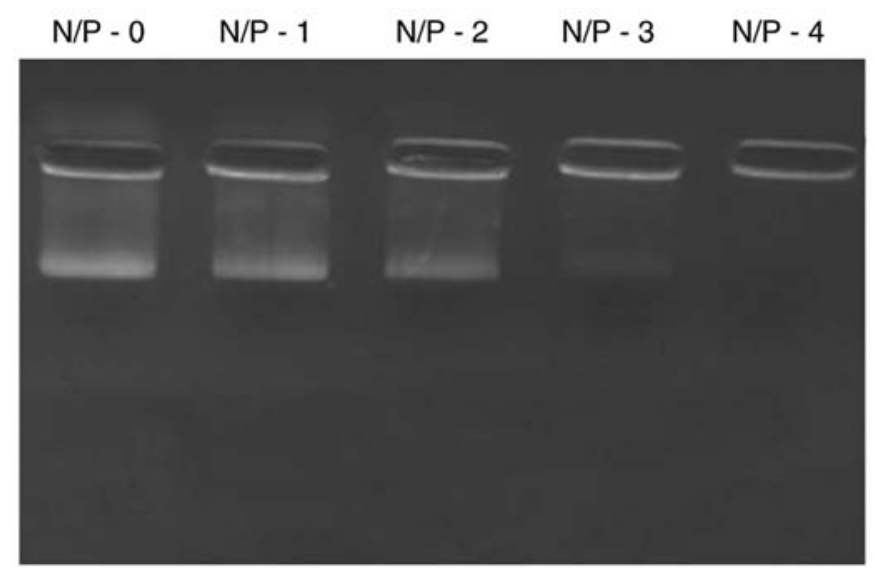

Figure 2. Gel electrophoresis of miRNA. The miRNA-loaded liposomes were evaluated for stability and degradation by gel electrophoresis. Increased N/P ratio indicates increased stability of miRNA. N, nitrogen; $\mathrm{P}$, phosphorous.

a size appropriate for accumulation in tumor tissue (24). The negatively charged miR-26a forms an electrostatic complex with the positively charged surfaces of the liposomes (Fig. 1) (25).

Dynamic light scattering (DLS) analysis was performed to characterize the final particle size and size distributions of the liposome preparations. As demonstrated in Fig. 3A, the particles were $110 \mathrm{~nm}$ in size, with a uniform dispersity index of 0.15 . The particle size of MRL was small enough for cancer-targeting applications (26). The surface charge of MRL was $+21.5 \pm 1.25 \mathrm{mV}$, indicating the presence of cationic charged liposomes. The dried particles were spherical in shape and dispersed. The particle size observed from TEM was consistent with that determined by DLS analysis (Fig. 3A). The positively charged liposomes were predicted to be internalized into the cancer cells, thereby further enhancing the efficacy of cancer treatment. The morphology of the particles was analyzed by TEM (Fig. 3B).

Gel electrophoresis. The loading of miR-26a into liposomes was confirmed by gel electrophoresis (Fig. 2). Free miRNA was electrophoresed to the opposite end of the gel, while loading of miRNA into liposomes prevented its release and migration in a concentration-dependent manner. The results indicated the ability of liposomes to withhold the encapsulated miRNA and thereby improve its stability and therapeutic efficacy. 

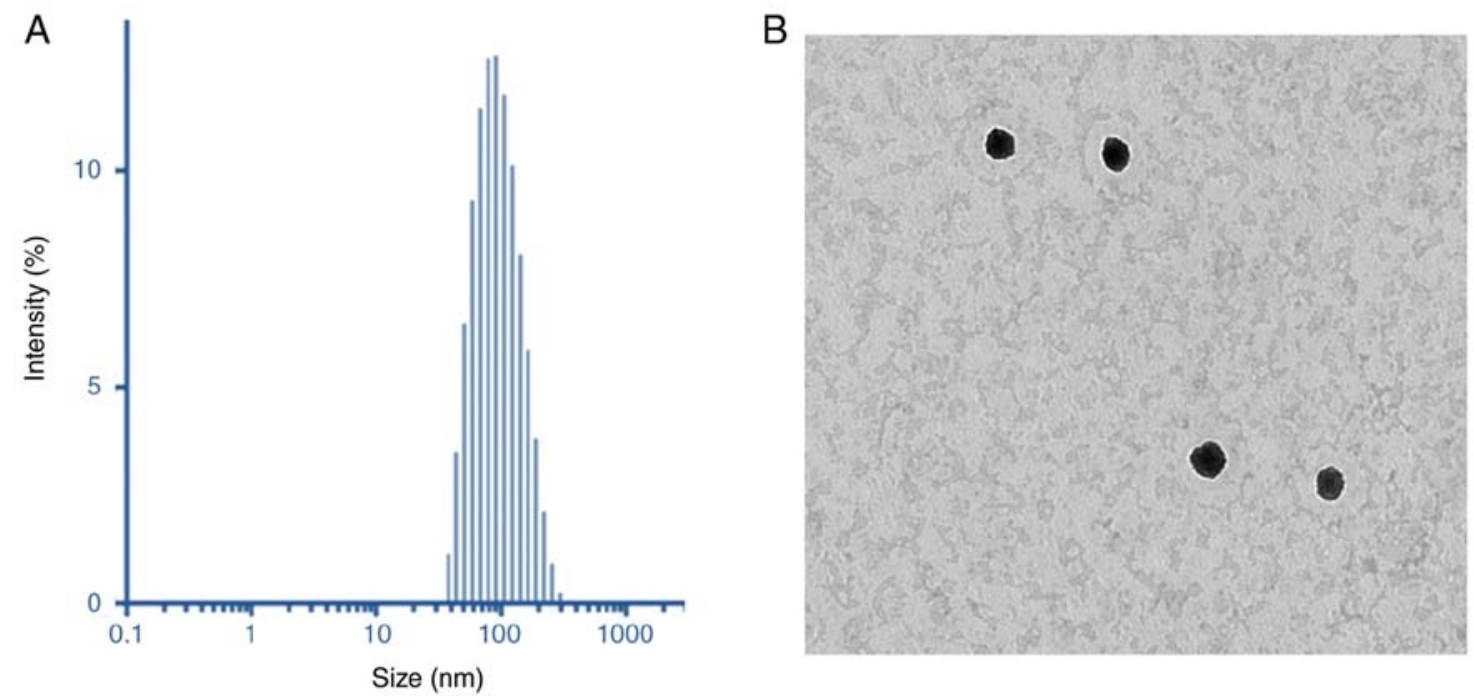

Figure 3. Physicochemical analysis. (A) Dynamic light scattering analysis of miRNA-loaded liposomes. (B) Particle morphology analysis by transmission electron microscopy revealed a spherical nanoparticle dimension.
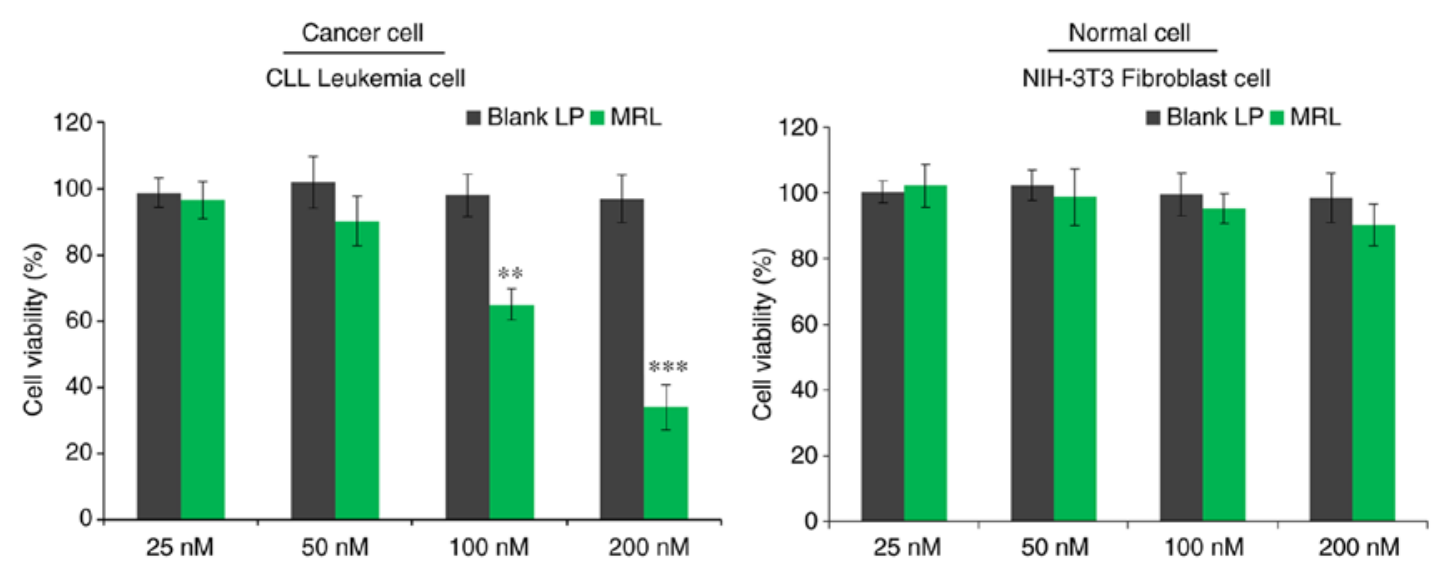

Figure 4. The cytotoxic potential of the miRNA-loaded liposomes was analyzed by MTT assay in CLL cancer cells treated with different concentrations of miRNA-26a. ${ }^{* *} \mathrm{P}<0.01,{ }^{* * *} \mathrm{P}<0.001$ vs. blank liposome. CLL, chronic lymphocytic leukemia; miRNA, microRNA; LP, liposome; MRL, miRNA-loaded liposome.

In vitro cell viability. The viability of CLL cells in vitro was evaluated by MTT assay (Fig. 4). Briefly, cells were treated with blank liposomes or miRNA-loaded liposomes and incubated for $24 \mathrm{~h}$. The control blank liposomes had no effect on the viability of cancer cells, indicating that the liposomes were non-toxic and biocompatible vectors. As expected, miRNA-26a-loaded liposomes decreased the viability of cancer cells in a concentration-dependent manner $(\mathrm{P}<0.001)$, with $>60 \%$ cells killed when treated with the highest concentration $(200 \mathrm{nM})$. The results indicated the anticancer effect of miRNA-26a against leukemia cells.

Hoechst 33342 assay. The anticancer effect of miRNA-26a was further evaluated by Hoechst 33342 staining (Fig. 5). Untreated cells maintained their typical morphology and dispersal on the plate, whereas treatment with miRNA-26a induced apoptosis in a concentration-dependent manner. Apoptosis of cancer cells was more evident with increasing concentrations of miRNA-26a (Fig. 5). For example, cells treated with $200 \mu \mathrm{M}$ miRNA exhibited typical apoptotic morphology, including condensation of chromatin, breakdown of the nuclear membrane, and apoptotic body formation. Taken together, these observations indicated the anticancer potential of miRNA-26a loaded within a stable nanocarrier.

Apoptotic rate, determined by flow cytometry. Quantitative analysis of apoptosis was performed by Annexin V/PI staining and flow cytometry (Fig. 6). Cancer cells were treated with $200 \mu \mathrm{M}$ miRNA for $24 \mathrm{~h}$. A significant $(\mathrm{P}<0.01)$ increase in apoptosis was observed compared with the control group. Approximately $25 \%$ of the total cells were in the late apoptotic stage, while $20 \%$ were in the early apoptosis stage, indicating the potent anticancer effect of the MRL formulation.

Western blot analysis. The mechanism of action of miRNA-26a was examined by western blotting (Fig. 7). The protein expression levels of target genes, cyclin-dependent kinase 6 (Cdk6) and myeloid cell leukemia 1 (Mcl-1), and the marker of apoptosis, PARP, were analyzed. The results indicated that high concentrations of miRNA-26a decreased the protein expression level of PARP and increased that of cleaved PARP, indicating the apoptosis-inducing potential of miRNA-26a. Seeing as miRNA-26a-loaded liposomes 

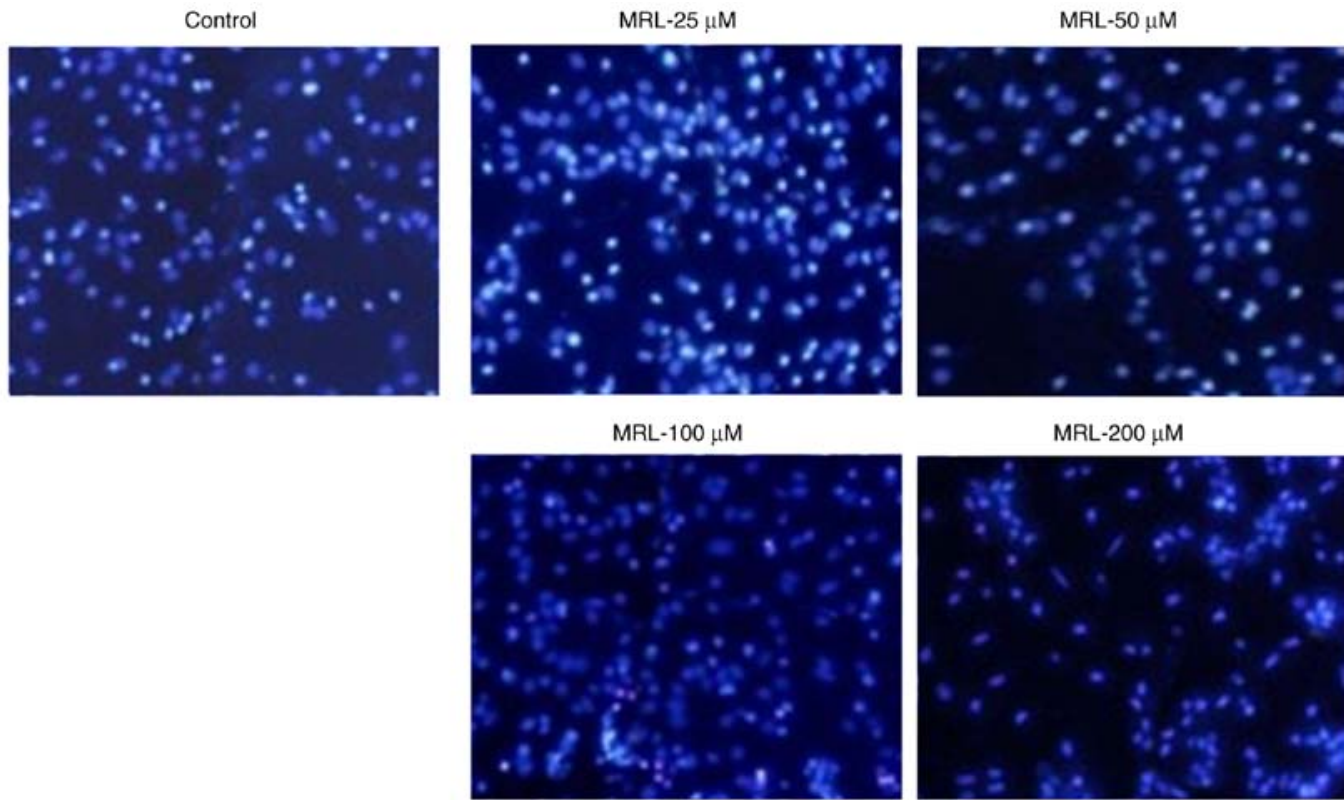

Figure 5. Apoptosis was qualitatively analyzed by Hoechst 33342 staining and fluorescence microscopy. Apoptotic body formation was observed in MRL-treated cells. MRL, miRNA-loaded liposome.
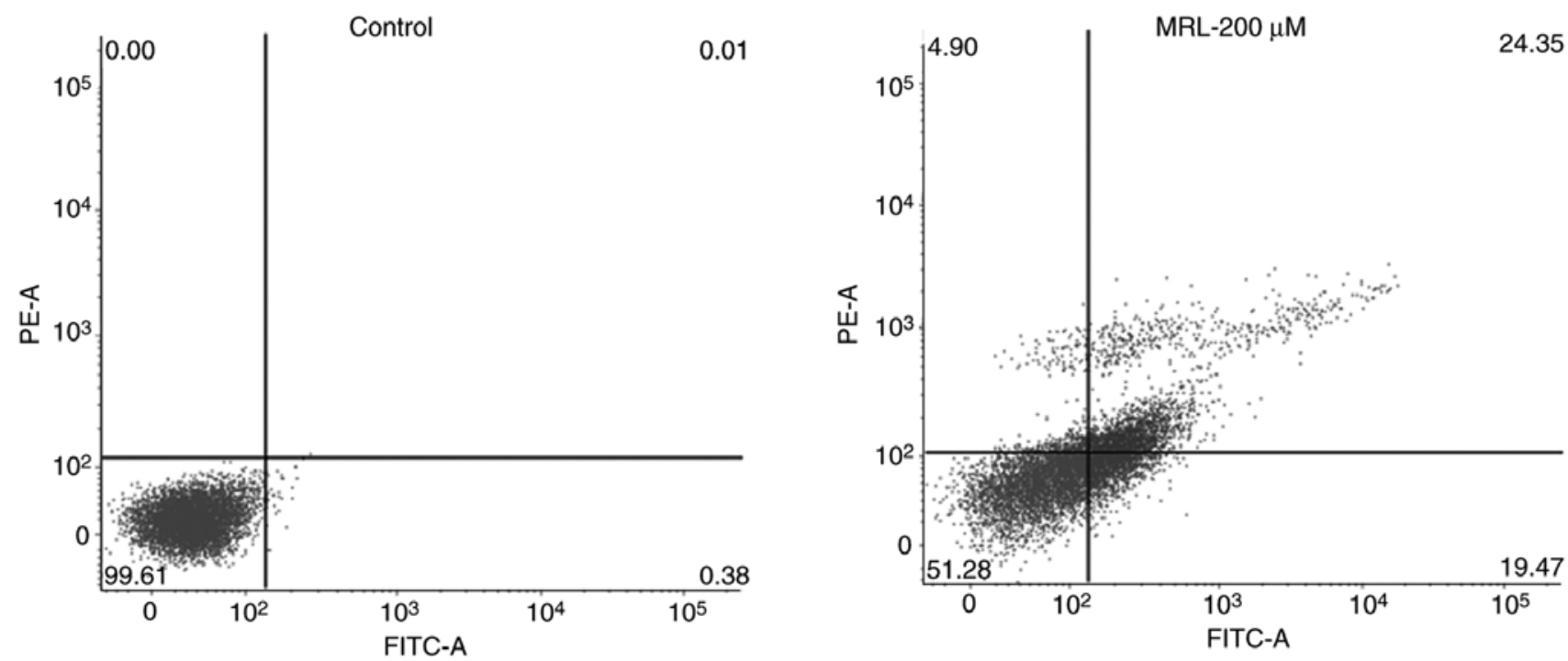

Figure 6. Quantitative analysis of apoptosis was performed by flow cytometry. The percentage distributions of cells in early and late apoptosis are indicated. MRL, miRNA-loaded liposome.
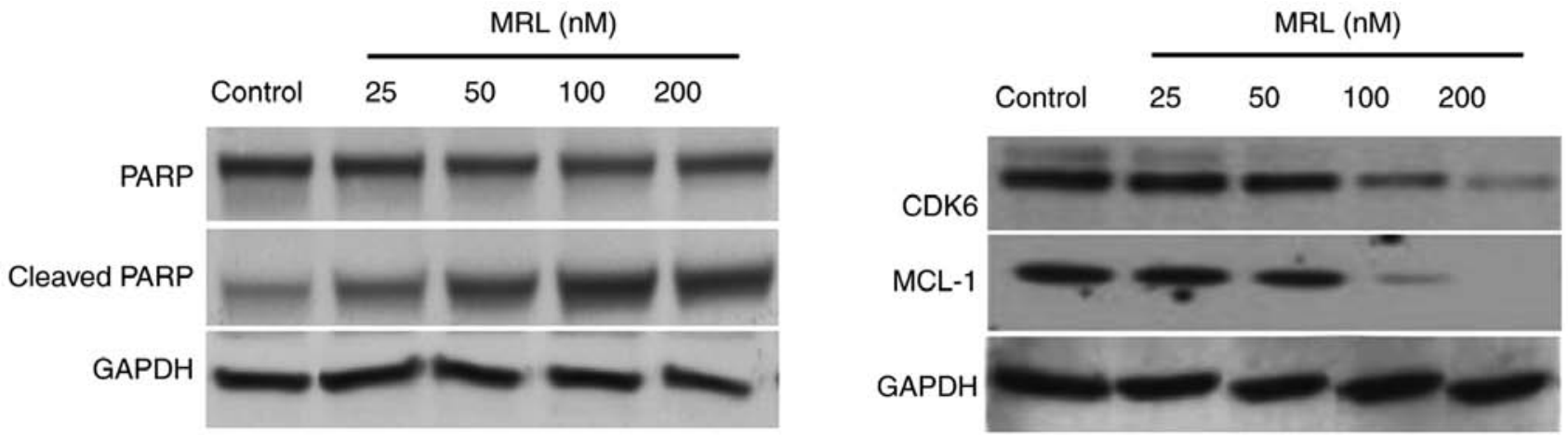

Figure 7. Western blotting analysis of the mechanism of action of miRNA-26q. The protein expression levels of apoptotic proteins and miRNA-26a targets were analyzed. MRL, miRNA-loaded liposome; PARP, poly (ADP-Ribose) polymerase; CDK6, cyclin-dependent kinase 6; MCL-1, MCL1, BCL2 family apoptosis regulator. 
significantly downregulated the expression of the target genes, Mcl-1 and Cdk6, this may be the mechanism of action by which it mediates apoptotic effect. Numerous studies have demonstrated that miR-26a can target and downregulate a number of protein-coding gene targets, including CDK6, cyclin D2 and E2, and Mcl-1, in different types of cancer cells $(27,28)$.

In conclusion, miRNA-26a-loaded liposomes successfully prepared for the effective treatment of leukemia cells. It was demonstrated that $200 \mathrm{nM}$ miRNA-26a significantly decreased the viability of CLL cells compared with control. The miRNA-26a-loaded liposomes exerted a marked apoptosis-inducing effect, as demonstrated by flow cytometry and Hoechst 33342 staining. Western blot analysis revealed a superior apoptosis-inducing effect of miRNA-26a-loaded liposomes compared with free miRNA-26a. miRNA-26a significantly downregulated the expression of its target genes, Mcl-1 and Cdk6. The results of the present study indicate that miRNA-26a-loaded liposomes exert apoptosis-inducing and anticancer effects on leukemia cells, suggesting their possible utility in future therapies. This approach has the potential for extrapolation to other types of neoplasms, including lymphomas and AML.

\section{Acknowledgements}

Not applicable.

\section{Funding}

The present study was supported by Shandong Blood Center (Shangdon, China).

\section{Availability of data and materials}

The datasets used and/or analysed during the current study are available from the corresponding author on reasonable request.

\section{Authors' contributions}

JL and CKS contributed equally to all research. CKS was responsible for the writing of the manuscript. All authors read and approved the final manuscript.

\section{Ethics approval and consent to participate}

Not applicable.

\section{Patient consent for publication}

Not applicable.

\section{Competing interests}

The authors declare that they have no competing interests.

\section{References}

1. Kwan JM, Fialho AM, Kundu M, Thomas J, Hong CS, Das Gupta TK and Chakrabarty AM: Bacterial proteins as potential drugs in the treatment of leukemia. Leuk Res 33 1392-1399, 2009.
2. Bhojwani D, Yang JJ and Pui CH: Biology of childhood acute lymphoblastic leukemia, Pediatr Clin North Am 62: 47-60, 2015.

3. Randhawa JK and Ferrajoli A: A review of supportive care and recommended preventive approaches for patients with chronic lymphocytic leukemia. Expert Rev Hematol 9: 235-244, 2016.

4. Morabito F, Gentile M, Seymour JF and Polliack A: Ibrutinib, idelalisib and obinutuzumab for the treatment of patients with chronic lymphocytic leukemia: Three new arrows aiming at the target. Leuk Lymphoma 56: 3250-3256, 2015.

5. Fabbri G and Dalla-Favera R: The molecular pathogenesis of chronic lymphocytic leukaemia. Nat Rev Cancer 16: 145-162, 2016.

6. Nimmanapalli R and Bhalla K: Novel targeted therapies for Bcr-Abl positive acute leukemias: Beyond STI571. Oncogene 21: 8584-8590, 2002.

7. Soni G and Yadav KS: Applications of nanoparticles in treatment and diagnosis of leukemia. Mater Sci Eng C 47: 156-164, 2015.

8. Terme M, Borg C, Guilhot F, Masurier C, Flament C, Wagner EF Caillat-Zucman S, Bernheim A, Turhan AG, Caignard A and Zitvogel L: BCR/ABL promotes dendritic cell-mediated natural killer cell activation. Cancer Res 65: 6409-6417, 2005.

9. Nagata Y and Todokoro K: Requirement of activation of JNK and p38 for environmental stress-induced erythroid differentiation and apoptosis and of inhibition of ERK for apoptosis. Blood 94: 853-863, 1999

10. Jia L, Patwari Y, Kelsey SM and Newland AC: Trail-induced apoptosis in Type I leukemic cells is not enhanced by overexpression of bax. Biochem Biophys Res Commun 283: 1037-1045, 2001.

11. Negrini M, Ferracin M, Sabbioni S and Croce CM: MicroRNAs in human cancer: From research to therapy. J Cell Sci 120: 1833-1840, 2007

12. Calin GA, Dumitru CD, Shimizu M, Bichi R, Zupo S, Noch E, Aldler H, Rattan S, Keating M, Rai K, et al: Frequent deletions and down-regulation of micro-RNA genes miR15 and miR16 at 13q14 in chronic lymphocytic leukemia. Proc Natl Acad Sci USA 99: 15524-15529, 2002.

13. Klein U, Lia M, Crespo M, Siegel R, Shen Q, Mo T, Ambesi-Impiombato A, Califano A, Migliazza A, Bhagat G and Dalla-Favera R: The DLEU2/miR-15a/16-1 cluster controls B cell proliferation and its deletion leads to chronic lymphocytic leukemia. Cancer Cell 17: 28-40, 2010.

14. Cimmino A, Calin GA, Fabbri M, Iorio MV, Ferracin M, Shimizu M, Wojcik SE, Aqeilan RI, Zupo S, Dono M, et al: miR-15 and miR-16 induce apoptosis by targeting BCL2. Proc Natl Acad Sci USA 102: 13944-13949, 2005.

15. Roberts AW, Davids MS, Pagel JM, Kahl BS, Puvvada SD, Gerecitano JF, Kipps TJ, Anderson MA, Brown JR, Gressick L, et al: Targeting BCL2 with venetoclax in relapsed chronic lymphocytic leukemia. N Engl J Med 374: 311-322, 2016.

16. Calin GA, Ferracin M, Cimmino A, Di Leva G, Shimizu M, Wojcik SE, Iorio MV, Visone R, Sever NI, Fabbri M, et al: A microRNA signature associated with prognosis and progression in chronic lymphocytic leukemia. N Engl J Med 353: 1793-1801, 2005.

17. Fabbri M, Bottoni A, Shimizu M, Spizzo R, Nicoloso MS, Rossi S, Barbarotto E, Cimmino A, Adair B, Wojcik SE, et al: Association of a microRNA/TP53 feedback circuitry with pathogenesis and outcome of B-cell chronic lymphocytic leukemia. JAMA 305: 59-67, 2011.

18. Ramasamy T, Ruttala HB, Gupta B, Poudel BK, Choi HG, Yong CS and Kim JO: Smart chemistry-based nanosized drug delivery systems for systemic applications: A comprehensive review. J Control Release 258: 226-253, 2017.

19. Choi JY, Ramasamy T, Tran TH, Ku SK, Shin BS, Choi HG, Yong CS and Kim JO: Systemic delivery of axitinib with nanohybrid liposomal nanoparticles inhibits hypoxic tumor growth. J Mater Chem B 3: 408-416, 2015.

20. Ramasamy T, Ruttala HB, Sundaramoorthy P, Poudel BK, Youn YS, Ku SK, Choi HG, Yong CS and Kim JO: Multimodal selenium nanoshell-capped $\mathrm{Au} @ \mathrm{mSiO}_{2}$ nanoplatform for NIR-responsive chemo-photothermal therapy against metastatic breast cancer. NPG Asia Mater 10: 197-216, 2018.

21. Ramasamy T, Haidar ZS, Tran TH, Choi JY, Choi HG, Jeong JH, Shin BS, Choi HG, Yong CS and Kim JO: Layer-by-layer assembly of liposomal nanoparticles with PEGylated polyelectrolytes enhances systemic delivery of multiple anticancer drugs. Acta Biomater 10: 5116-5127, 2014. 
22. Chen Y, Gao DY and Huang L: In vivo delivery of miRNAs for cancer therapy: Challenges and strategies. Adv Drug Deliv Rev 81: 128-141, 2015.

23. Lam JK, Chow MY, Zhang Y and Leung SW: siRNA versus miRNA as therapeutics for gene silencing. Mol Ther Nucleic Acids 4: e252, 2015.

24. Ruttala HB, Ramasamy T,Madeshwaran T,Hiep TT,Kandasamy U, Oh KT, Choi HG, Yong CS and Kim JO: Emerging potential of stimulus-responsive nanosized anticancer drug delivery systems for systemic applications. Arch Pharm Res 41: 111-129, 2018.

25. Ahmadzada T, Reid G and McKenzie DR: Fundamentals of siRNA and miRNA therapeutics and a review of targeted nanoparticle delivery systems in breast cancer. Biophys Rev 10: 69-86, 2018.

26. Ganju A, Khan S, Hafeez BB, Behrman SW, Yallapu MM, Chauhan SC and Jaggi MM: miRNA nanotherapeutics for cancer. Drug Discov Today 22: 424-432, 2017.
27. Yang X, Liang L, Zhang XF, Jia HL, Qin Y, Zhu XC, Gao XM, Qiao P, Zheng Y, Sheng YY, et al: MicroRNA-26a suppresses tumor growth and metastasis of human hepatocellular carcinoma by targeting interleukin-6-Stat3 pathway. Hepatology 58: 158-170, 2013.

28. Zhu Y, Lu Y, Zhang Q, Liu JJ, Li TJ, Yang JR, Zeng C and Zhuang SM: MicroRNA-26a/b and their host genes cooperate to inhibit the G1/S transition by activating the $\mathrm{pRb}$ protein. Nucleic Acids Res 40: 4615-4625, 2012.

This work is licensed under a Creative Commons Attribution-NonCommercial-NoDerivatives 4.0 International (CC BY-NC-ND 4.0) License. 